\title{
Refractory Bleeding from Peptic Ulcers: Is There Still a Role for Surgery?
}

\author{
Romaric Loffroy Boris Guiu \\ Division of Interventional Radiology and Endovascular Therapy, University of Dijon School of Medicine, \\ Bocage Teaching Hospital, Dijon, France
}

Dear Sir,

We read with great interest the article by Chiu et al. [1] published recently in $\mathrm{Di}$ gestive Surgery, which reported the role of the surgical salvage of bleeding peptic ulcers after endoscopic treatment failure. We have several comments and questions. Endoscopy is the first-line method for diagnosing and treating actively bleeding peptic ulcers because its success rate is high. Recent advances in endoscopic hemostasis techniques ensure bleeding control in most patients. Endoscopic treatment combined with adjunctive high-dose proton pump inhibitors is particularly valuable in patients whose advanced age or comorbid conditions pose a high surgical risk. When endoscopy fails, surgery is associated with mortality rates as high as 20-40\% [2]. Therefore, endovascular embolization has generated interest as an alternative to surgery in high-risk patients with bleeding despite endoscopic treatment. The use of endovascular embolization is supported by the technical advances, high clinical success rates in our last study (95 and $71.9 \%$, respectively) [3] as well as in all published case series over the last decade [4-6]. Consequently, we are very surprised in this study that angiography followed by arterial embolization was not systematically used first in patients who failed hemostasis after repeat endos- copy. Endovascular treatment has the advantage of avoiding postsurgical morbidity, most notably complications related to the surgical method and infectious complications. Indeed, Chiu et al. [1] reported high rates of complications and 30-day mortality whatever the surgical approach used, minimal or definitive, and the period of the study, group 1 (1993-1998) or group 2 (1999-2004). The highest morbidity $(47.6 \%)$ and mortality $(40.5 \%)$ rates were reported in the second cohort, whereas minimal surgery was performed in the majority of cases, with a re-bleeding rate of $38 \%$. Then, the median length of hospital stay (20.26 days) correlated with these data. These results are not acceptable. We recently reported our results obtained during nearly 10 years of experience with arterial embolization used to treat refractory massive bleeding from gastroduodenal ulcers [3]. We had 60 critically ill patients with a mean age of 69.4 years, the largest case series in the literature. The complications and 1-month mortality rates were 10 and $26.7 \%$, respectively, with a re-bleeding rate of $28 \%$. Only $7(11.6 \%)$ of the 60 patients needed surgery after failure of embolization procedures. So we do not understand why an endovascular approach was not used by the authors to treat these poor surgical candidates because it could have resulted in lower periprocedural morbidity and mortality. In addition, we showed that embolization was effective not only in controlling the acute bleeding episode, but also in preventing recurrences in the long-term. Did the authors use endovascular embolization between 1993 and 2004, and exclude patients treated with this approach from the study? Did the authors use an endovascular approach more recently as first choice for treating bleeding from gastroduodenal ulcers after failed therapeutic endoscopy, especially since 2004? In our institution, this technique is now the salvage treatment of choice after failure of an endoscopic procedure. In most cases, embolization obviates the need for surgery in critically ill patients whose immediate survival depends on their underlying conditions. In conclusion, we do not agree with Chiu et al. [1] about the use of surgery, even when minimal, as the first-line method for treating massively bleeding peptic ulcers. We think that surgical treatment should be performed only as a last resort after failure of endoscopic and endovascular procedures.

\section{KARGER}

(ㄷ) 2009 S. Karger AG, Basel

0253-4886/09/0265-0437\$26.00/0

Fax +41613061234 E-Mail karger@karger.ch www.karger.com
Romaric Loffroy, MD

Division of Interventional Radiology and Endovascular Therapy University of Dijon School of Medicine, Bocage Teaching Hospital

2 bd du Maréchal de Lattre de Tassigny, BP 77908, FR-21079 Dijon Cedex (France)

Tel. +33 380293 686, Fax +33 380293 243, E-Mail romaric.loffroy@ chu-dijon.fr 


\section{References}

1 Chiu PW, Ng EK, Wong SK, et al: Surgical salvage of bleeding peptic ulcers after failed therapeutic endoscopy. Dig Surg 2009;26: 243-248.

2 Kubba AK, Choudari C, Rajgopal C, Palmer KR: The outcome of urgent surgery for major peptic ulcer hemorrhage following failed endoscopic therapy. Eur J Gastroenterol Hepatol 1996;8:1175-1178.
3 Loffroy R, Guiu B, D'Athis P, et al: Arterial embolotherapy for endoscopically unmanageable acute gastroduodenal hemorrhage: predictors of early rebleeding. Clin Gastroenterol Hepatol 2009;7:515-523.

4 Loffroy R, Guiu B, Cercueil JP, et al: Refractory bleeding from gastroduodenal ulcers: arterial embolization in high-operative-risk patients. J Clin Gastroenterol 2008;42:361367.
5 Larssen L, Moger T, Bjornbeth BA, Lygren I, Klow NE: Transcatheter arterial embolization in the management of bleeding duodenal ulcers: a 5.5-year retrospective study of treatment and outcome. Scand J Gastroenterol 2008;43:217-222.

6 Van Vugt R, Bosscha K, van Munster IP, de Jager CP, Rutten MJ: Embolization as treatment of choice for bleeding peptic ulcers in high-risk patients. Dig Surg 2009;26:37-41. 